\title{
High seroprevalence of SARS-CoV-2 among high-density communities in Saudi Arabia
}

\author{
Sami Almudarra ${ }^{1} \cdot$ Shady Kamel $^{2} \cdot$ Eman Saleh $^{3} \cdot$ Rehab Alaswad $^{4} \cdot$ Amaal Alruwaily $^{4} \cdot$ Shaza Almowald $^{4}$. \\ Ada Mohammed Alqunaibet ${ }^{4} \cdot$ Abdullah Almudiaheem $^{4} \cdot$ Hind Almutlaq $^{4} \cdot$ Haleema Alserehi ${ }^{4}$. \\ Safar Almalki ${ }^{5}$. Mohannad Abdulhafiz Bahlaq ${ }^{6} \cdot$ Abdullah Jaber Alsahafi $^{7} \cdot$ Faisal Alsaif $^{8} \cdot$ Abdullah T. Khojah $^{9}$. \\ Jaffar A. Al-Tawfiq ${ }^{10,11,12}$ - Sari Ibrahim Asiri ${ }^{13} \cdot$ Abdullah Assiri $^{14} \cdot$ Hani Jokhdar ${ }^{15}$
}

Received: 25 August 2021 / Accepted: 26 October 2021 / Published online: 8 December 2021

(c) The Author(s), under exclusive licence to Springer-Verlag GmbH Germany 2021

\begin{abstract}
Background The Severe Acute Respiratory Syndrome Coronavirus 2 (SARS-CoV-2) infection had been investigated utilizing serology.

Materials and methods This community-based sero-survey was carried out in the neighborhoods of three cities in Saudi Arabia.

Results Of 5629 participants, 2766 (49.1\%) were women; and 2148 (38.1\%) were 18-34 years of age, and 3645 (64.7\%) were from South East Asia. Positive serology was seen in 2825 (50.2\% (95\% CI: 48.8-51.5\%) for SARS-CoV-2 anti-S1 IgG antibodies by ECLIA. Being in the age category of 18-34 years and being from Eastern Mediterranean Region (country A) were associated with higher COVID-19 seropositivity with estimated odds ratio of 1.3 [95\% CI 1.1-1.8] and 2.5 [95\% CI 1.1.5-4.2] respectively. Gender, social status, education, nationality, symptoms, presence of comorbidities and activity style were positively associated with increased seropositivity. Factors associated negatively with the rate of seropositivity were higher education and having outdoor activity with estimated OR of 0.92 [95\% CI 0.46-0.95] and 0.59 [95\% CI 0.47-0.74], respectively.

Conclusion The study showed high seroprevalence of SARS-CoV-2 among high density population. Health education campaigns should target middle-aged, those with low education, those living in lower standards and indoor workers.
\end{abstract}

Keywords SARS-CoV-2 $\cdot$ Serology $\cdot$ High density $\cdot$ COVID-19

Jaffar A. Al-Tawfiq

jaffar.tawfiq@jhah.com

1 Public Health Agency, Saudi Ministry of Health, Riyadh, Saudi Arabia

2 Field Epidemiology Training Program, Public Health Agency, Saudi Ministry of Health, Riyadh, Saudi Arabia

3 Department of Public Health and Community Medicine, Faculty of Medicine, Mansoura University, Mansoura, Egypt

4 Saudi Center of Disease Prevention and Control, Riyadh, Saudi Arabia

5 Ministry of Health Laboratories, Saudi Ministry of Health, Riyadh, Saudi Arabia

6 Public Health Deputy, Madinah Directorate of Health Affairs, Saudi Ministry of Health, Riyadh, Saudi Arabia

7 Public Health Deputy, Jeddah Directorate of Health Affairs, Saudi Ministry of Health, Riyadh, Saudi Arabia
8 College of Medicine, King Saud University, Riyadh, Saudi Arabia

9 Faculty of Medicine, Al Imam Muhammad ibn Saud Islamic University, Riyadh, Saudi Arabia

10 Infectious Disease Unit, Specialty Internal Medicine, Johns Hopkins Aramco Healthcare, Dhahran, Saudi Arabia

11 Infectious Disease Division, Department of Medicine, Indiana University School of Medicine, Indianapolis, IN, USA

12 Infectious Disease Division, Department of Medicine, Johns Hopkins University, Baltimore, MD, USA

13 Saudi Ministry of Health, Riyadh, Saudi Arabia

14 Public Health Agency, Saudi Ministry of Health, Riyadh, Saudi Arabia

15 Public Health Agency, Saudi Ministry of Health, Riyadh, Saudi Arabia 


\section{Introduction}

The Severe Acute Respiratory Syndrome Coronavirus 2 (SARS-CoV-2) results in a wide spectrum of symptoms including: fever, asthenia, myalgia, pneumonia, and acute respiratory distress syndrome as well as asymptomatic infection [1]. In low-income and middle-income countries, structural and institutional inadequacies may result in the rapid spread of the virus with a heightened risk of community transmission [2, 3] and subsequent outcome disparity [3, 4]. There are multiple reasons behind increased transmission of SARS-CoV-2 in slums and include: overcrowding, close contact, and poor sanitation. While tight restrictions on movement may reduce SARS-CoV-2 transmission, there are social and economic consequences of locking down slums with a subsequent impact on access to healthcare [2].

To mitigate the COVID-19 pandemic, emphasis has been laid on hand hygiene using alcohol-based hand rub or soap and water. Physical distancing, keeping at least $2 \mathrm{~m}$ away from the nearest person, and applying cough etiquette also had been adopted as a COVID-19 preventive measure. These measures however remain a significant challenge given the inherent nature of slums and overcrowded areas, coupled with inadequate access to safe water and basic sanitation. The recommended home stay is just not an option for urban slum dwellers, as this often means giving up work and necessities [5].

Estimating the prevalence of Coronavirus Virus Disease 2019 (COVID-19) is critical for understanding the overall distribution and the presence of hotspots of SARS-CoV-2. Population-based serological data are essential for understanding the prevalence of subclinical infections and the population's herd immunity against SARS-CoV-2 [6-8]. Seroprevalence of SARS-CoV-2 might also help in risk stratifications based on age, geographic location, or underlying health conditions to develop preventive strategies.

Here, we study the seroprevalence of SARS-CoV-2 in condensed districts in three cities in the Kingdom of Saudi Arabia. The objectives of this study were to determine the magnitude of COVID-19 cases among neighborhoods of high density communities and to identify the epidemiological characteristics and risk factors associated with positive serology. The result of this study would increase our understanding of the prevalence of SARS-CoV-2 infection to implement strategies for prevention, control and vaccination prioritization [9].

\section{Methods}

A community-based serosurvey was carried out in three cities in Saudi Arabia. Blood samples were collected through mobile clinics for serology and tested at the Ministry of Health $(\mathrm{MOH})$ regional laboratories. Also, a structured standardized questionnaire [10] was filled to gather information about: demographics, notification information (area/district), clinical information (symptoms, time of onsets, medical history) and epidemiological information (movements history, contact exposure). Data were entered and analyzed using (SPSS) version 21. The study was conducted over 2 weeks in August 2020 before the start of the COVID-19 vaccination in Saudi Arabia which was started in December $2020[9,11,12]$. A $P$ value $<0.05$ indicated statistical significance.

We asked the residents in these neighborhoods to participate voluntarily without any restrictions related to gender, age or nationality. In addition, we included those who had prior positive SARS-CoV-2 PCR result, and had been without symptoms for $\geq 14$ days, and also include those who were never tested for SARS-CoV-2 and were asymptomatic. We excluded symptomatic and those who were previously labelled as COVID-19 cases and had not completed 14 days.

\section{Sampling technique}

Randomly, we selected participants from the list of the neighborhood. The selected individuals were interviewed by the assigned $\mathrm{MOH}$ team members. Each selected participant in area/district gave a verbal consent to participate in the study anonymously. Each participant filled the questionnaire as described previously [6]. One blood sample of $4 \mathrm{ml}$ was obtained for serology testing. Serum samples were transported refrigerated at $2-8{ }^{\circ} \mathrm{C}$. However, if there was a delay then samples were frozen at -20 to $-80{ }^{\circ} \mathrm{C}$ and were shipped on dry ice. Anti-SARS-CoV-2 antibodies were detected by an electrochemiluminescent immunoassay (ECLIA) using the Elecsys ${ }^{\circledR}$ test from Roche Diagnostics International Ltd. (Rotkreuz, Switzerland) for the detection of anti-N IgG antibodies, as described previously [6]. The antibody test for SARS-CoV-2 generally detects antibodies using a recombinant protein representing the nucleocapsid (N) or the S proteins of SARS-CoV-2 [13-15]. The study was approved by the Ministry of health Central Institutional Review Board (H-01-R-009). 


\section{Results}

We enrolled 5792 individuals, including household members of neighborhoods in 3 cities (A, B and C). However, only 5629 had completed the questionnaires, had serology tests and were included in further analysis. Of those who completed the questionnaire, 2766 (49.1\%) were women; and $2148(38.1 \%)$ were $18-34$ years of age, 1720 (30.5\%) were 35-54 years of age; and $3645(64.7 \%)$ were from South East Asia (country 1), and 721 (12.8\%) were from Eastern Mediterranean Region (country C) (Table 1).

A total of 2825 [50.2\% (95\% CI 48.8-51.5\%)] tested positive for SARS-CoV-2 anti-N IgG antibodies by ECLIA. The positivity rate per city was as follows: 1633 of $2498(65.4 \%)$ [ $95 \%$ CI 63.4-67.2\%] for city A, 504 of $1490(33.8 \%)$ [ $95 \%$ CI $31.4 \%-36.3 \%$ ] for city B, and 688 of 1642 (41.9\%) [95\% CI 39.5\%-44.3\%] for City C (Table 1). In univariate analyses, Table 1 reveals that there was statistically significant difference between those having positive and negative serology in relation to age, gender, social status, education, nationality and recruitment city $(P=<0.0001)$. It is interesting to note that females had higher positivity rate than males $(50.4 \%$ vs. $42.86 \%$; respectively; $P<0.0001)$. In relation to symptoms, 80 (36.4\%) of 220 with symptoms and 2745 (50.7\%) without symptoms were seropositive $(P<0.0001)$, and $108(36 \%)$ of 300 with symptoms vs. 2717 (51\%) of 5329 without symptoms were seropositive $(P<0.0001)$. In addition, 137 (28.7\%) of 337 with frequent outdoor contacts vs. 1055 (39.6\%) of 2657 without frequent outdoor contacts were seropositive $(P<0.0001)$.

In addition, there was statistically significant difference between positive and negative groups in relation to history of fever, runny nose, loss of smell/taste and headache (Table 2). Having hypertension or diabetes mellitus, was statistically different between the two groups (Table 3). Contact history to confirmed or recovered cases, attending any gatherings or healthcare facilities showed no significant difference between sero-positive and sero-negative groups (Table 4). Overall seropositivity was significantly $\left(\chi^{2}=19.78, P\right.$ value $<0.0001)$ higher among those from South East Asia (Country 1) (52.37\%) compared to others nationalities (30.7\%) (Table 5).

Multivariate analysis revealed that age of 18-34 years was more likely to have COVID-19 seropositivity with estimated odds ratio of 1.3 [95\% CI 1.1-1.8]. Moreover, being of Eastern Mediterranean Region (country

Table 1 Socio-demographic factors among the study participants

\begin{tabular}{|c|c|c|c|c|c|c|}
\hline \multirow[t]{3}{*}{ Item } & \multirow[t]{3}{*}{ Category } & \multirow[t]{3}{*}{ Total number } & \multicolumn{2}{|c|}{ Test result } & \multirow[t]{3}{*}{$\chi^{2}$} & \multirow[t]{3}{*}{$P$ value } \\
\hline & & & \multicolumn{2}{|l|}{ Positive } & & \\
\hline & & & Number & $\%$ & & \\
\hline \multirow[t]{4}{*}{ Age in years } & $\leq 17$ & 239 & 125 & 52.3 & \multirow[t]{4}{*}{75.08} & \multirow[t]{4}{*}{$<0.0001$} \\
\hline & $>55$ & 261 & 124 & 47.51 & & \\
\hline & $18-34$ & 2148 & 1196 & 55.68 & & \\
\hline & $35-54$ & 1720 & 870 & 50.58 & & \\
\hline \multirow[t]{2}{*}{ Gender } & Male & 161 & 69 & 42.86 & \multirow[t]{2}{*}{3.56} & \multirow[t]{2}{*}{$<0.0001^{*}$} \\
\hline & Female & 5468 & 2756 & 50.4 & & \\
\hline \multirow[t]{2}{*}{ Social status } & Married & 3586 & 1695 & 47.27 & \multirow[t]{2}{*}{41.3} & \multirow[t]{2}{*}{$<0.0001^{*}$} \\
\hline & Single & 1955 & 1094 & 55.96 & & \\
\hline \multirow[t]{3}{*}{ Education } & High school & 536 & 221 & 41.23 & \multirow[t]{3}{*}{383.16} & \multirow[t]{3}{*}{$<0.0001^{*}$} \\
\hline & Less than high & 2110 & 765 & 36.26 & & \\
\hline & More than High & 371 & 168 & 45.28 & & \\
\hline \multirow[t]{6}{*}{ WHO Origin } & South East Asia (Country 2) & 384 & 255 & 66.41 & \multirow[t]{5}{*}{140.36} & \multirow[t]{6}{*}{$<0.0001^{*}$} \\
\hline & South East Asia (Country 1) & 3645 & 1909 & 52.37 & & \\
\hline & Eastern Mediterranean Region (Country C) & 1346 & 584 & 43.4 & & \\
\hline & Eastern Mediterranean Region (Country A) & 202 & 63 & 31.19 & & \\
\hline & Eastern Mediterranean Region (Country B) & & & & & \\
\hline & Other & 254 & 77 & 30.31 & & \\
\hline \multirow[t]{3}{*}{ City } & City A & 2498 & 1633 & 65.37 & \multirow[t]{3}{*}{434.76} & \multirow[t]{3}{*}{$<0.0001^{*}$} \\
\hline & City B & 1490 & 504 & 33.83 & & \\
\hline & City C & 1641 & 688 & 41.93 & & \\
\hline
\end{tabular}

*Statistically significant 
Table 2 Seropositivity by symptoms (more than 14 days prior to enrollment in the study) among the study participants

\begin{tabular}{|c|c|c|c|c|c|}
\hline \multirow[t]{2}{*}{ Symptom } & \multirow{2}{*}{$\begin{array}{l}\text { Total } \\
\text { Number }\end{array}$} & \multicolumn{2}{|l|}{ Positive } & \multirow[t]{2}{*}{$\chi^{2}$} & \multirow[t]{2}{*}{$P$ value } \\
\hline & & Number & $\%$ & & \\
\hline \multicolumn{6}{|c|}{ Temperature } \\
\hline No & 5511 & 2786 & 50.55 & 10.18 & $0.001^{*}$ \\
\hline Yes & 106 & 37 & 34.91 & & \\
\hline \multicolumn{6}{|c|}{ Sore throat } \\
\hline No & 5594 & 2813 & 50.29 & 3.55 & 0.059 \\
\hline Yes & 35 & 12 & 34.29 & & \\
\hline \multicolumn{6}{|c|}{ Runny nose } \\
\hline No & 3972 & 2133 & 53.7 & 5.27 & $0.022 *$ \\
\hline Yes & 16 & 4 & 25 & & \\
\hline \multicolumn{6}{|l|}{ Cough } \\
\hline No & 3937 & 2114 & 53.7 & 1.49 & 0.22 \\
\hline Yes & 51 & 23 & 45.1 & & \\
\hline \multicolumn{6}{|l|}{ Dyspnea } \\
\hline No & 3969 & 2130 & 53.67 & 2.15 & 0.14 \\
\hline Yes & 19 & 7 & 36.84 & & \\
\hline \multicolumn{6}{|l|}{ Nausea } \\
\hline No & 3984 & 2136 & 53.61 & 1.31 & 0.25 \\
\hline Yes & 4 & 1 & 25 & & \\
\hline \multicolumn{6}{|c|}{ Loss of smell/taste } \\
\hline No & 3974 & 2135 & 53.72 & 8.72 & $0.003 *$ \\
\hline Yes & 14 & 2 & 14.29 & & \\
\hline \multicolumn{6}{|l|}{ Headache } \\
\hline No & 3956 & 2126 & 53.74 & 4.78 & $0.029 *$ \\
\hline Yes & 32 & 11 & 34.38 & & \\
\hline \multicolumn{6}{|l|}{ Joint pain } \\
\hline No & 3979 & 2134 & 53.63 & 1.48 & 0.223 \\
\hline Yes & 9 & 3 & 33.33 & & \\
\hline \multicolumn{6}{|c|}{ Muscle ache } \\
\hline No & 3978 & 2132 & 53.59 & 0.052 & 0.82 \\
\hline Yes & 10 & 5 & 50 & & \\
\hline \multicolumn{6}{|l|}{ Diarrhea } \\
\hline No & 3987 & 2137 & 53.6 & 1.15 & 0.28 \\
\hline Yes & 1 & 0 & 0 & & \\
\hline \multicolumn{6}{|c|}{ Other symptoms } \\
\hline No & 1488 & 503 & 33.8 & 0.51 & 0.47 \\
\hline Yes & 1 & 0 & 0 & & \\
\hline
\end{tabular}

*Statistically significant

A) nationality was a significant positive predictor of seropositivity, with estimated odds ratio of 2.5 [95\% CI 1.1.5-4.2]. On the other hand, significant negative predictors were educational level (being with more than high school) and being employee of outdoor activity were less likely to have seropositive results with estimated OR of 0.92 [95\% CI 0.46-0.95] and 0.59[95\% CI 0.47-0.74], respectively (Table 6).
Table 3 Seropositivity by underlying comorbidities among the study participants

\begin{tabular}{|c|c|c|c|c|c|}
\hline \multirow[t]{2}{*}{ Comorbidity } & \multirow{2}{*}{$\begin{array}{l}\text { Total } \\
\text { Number }\end{array}$} & \multicolumn{2}{|l|}{ Positive } & \multirow[t]{2}{*}{$\chi^{2}$} & \multirow[t]{2}{*}{$P$ value } \\
\hline & & Number & $\%$ & & \\
\hline \multicolumn{6}{|c|}{ Chronic vascular disease } \\
\hline No & 5611 & 2818 & 50.22 & 0.92 & 0.33 \\
\hline Yes & 18 & 7 & 38.89 & & \\
\hline \multicolumn{6}{|l|}{ Hypertension } \\
\hline No & 5482 & 2771 & 50.55 & 10.92 & $0.001^{*}$ \\
\hline Yes & 147 & 54 & 36.73 & & \\
\hline \multicolumn{6}{|c|}{ Diabetes mellitus } \\
\hline No & 5415 & 2747 & 50.73 & 16.79 & $<0.0001^{*}$ \\
\hline Yes & 214 & 78 & 36.45 & & \\
\hline \multicolumn{6}{|c|}{ Chronic renal disease } \\
\hline No & 5629 & 2825 & 50.19 & - & - \\
\hline Yes & 0 & 0 & 0 & & \\
\hline \multicolumn{6}{|c|}{ Chronic liver disease } \\
\hline No & 5628 & 2825 & 50.2 & 1.01 & 0.31 \\
\hline Yes & 1 & 0 & 0 & & \\
\hline \multicolumn{6}{|c|}{ Immuno-compromised } \\
\hline No & 5629 & 2825 & 50.19 & - & - \\
\hline Yes & 0 & 0 & 0 & & \\
\hline \multicolumn{6}{|c|}{ Other comorbidities } \\
\hline No & 5617 & 2822 & 50.24 & 3.05 & 0.08 \\
\hline
\end{tabular}

*Statistically significant

Table 4 Seropositivity by contact history (more than 14 days prior to enrollment in the study) with confirmed cases among the study participants

\begin{tabular}{|c|c|c|c|c|}
\hline \multirow[t]{2}{*}{ Exposure } & \multicolumn{2}{|l|}{ Positive } & \multirow[t]{2}{*}{$\chi^{2}$} & \multirow[t]{2}{*}{$P$ value } \\
\hline & Number & $\%$ & & \\
\hline \multicolumn{5}{|c|}{ Contact with confirmed case } \\
\hline No (3122) & 1187 & 37.9 & 1.17 & 0.27 \\
\hline Yes (9) & 5 & 55.6 & & \\
\hline \multicolumn{5}{|c|}{ Contact with recovered case } \\
\hline No (3101) & 1182 & 38 & 0.28 & 0.59 \\
\hline Yes (30) & 10 & 33.3 & & \\
\hline \multicolumn{5}{|c|}{ Attending gatherings } \\
\hline No (3122) & 1189 & 38 & 0.086 & 0.76 \\
\hline Yes (9) & 3 & 33.3 & & \\
\hline \multicolumn{5}{|c|}{ Visiting healthcare facility } \\
\hline No (5556) & 2797 & 48.9 & 3.8 & 0.5 \\
\hline Yes (70) & 27 & 38.6 & & \\
\hline
\end{tabular}

\section{Discussion}

The use of a serological test to detect anti-SARS-CoV-2 antibodies could be a better way to estimate the burden 
Table 5 Seropositivity by geographical distribution of the study participants in comparison to South East Asia (Country 1)

\begin{tabular}{|c|c|c|c|c|}
\hline \multirow[t]{2}{*}{ Distribution } & \multicolumn{2}{|l|}{ Positive } & \multirow[t]{2}{*}{$\chi^{2}$} & \multirow[t]{2}{*}{$P$ value } \\
\hline & Number & $\%$ & & \\
\hline \multicolumn{5}{|l|}{ City A } \\
\hline South East Asia (Country 1) (2182) & 1418 & 64.99 & 3.62 & 0.057 \\
\hline Other (316) & 215 & 68.04 & & \\
\hline \multicolumn{5}{|l|}{ City B } \\
\hline South East Asia (Country 1) (1458) & 491 & 33.68 & 0.675 & 0.411 \\
\hline Other (32) & 13 & 40.63 & & \\
\hline \multicolumn{5}{|l|}{ City C } \\
\hline South East Asia (Country 1) (5) & 0 & 0 & - & - \\
\hline Other (1636) & 688 & 42.05 & & \\
\hline \multicolumn{5}{|l|}{ All cities } \\
\hline South East Asia (Country 1) (3645) & 1909 & $\begin{array}{l}52.37 \text { [95\% CI } \\
50.74-54.01 \%]\end{array}$ & 19.78 & $<0.0001$ \\
\hline Other (1984) & 916 & 46.17 & & \\
\hline
\end{tabular}

\begin{tabular}{lllc}
\hline Predictor & $\beta$ & $\begin{array}{l}\text { Exp.(B)/adjusted odds } \\
\text { ratio }(95 \% \text { CI })\end{array}$ & $P$ value \\
\hline Age category & & & \\
$\leq 17^{*}$ & & & \\
$18-34$ & 0.305 & $1.357(1.015-1.812)$ & $0.039^{*}$ \\
$35-54$ & 0.177 & $1.194(0.908-1.570)$ & 0.204 \\
$>55$ & 0.226 & $1.254(0.774-2.031)$ & 0.357 \\
WHO Origin & & & $0.015^{*}$ \\
South East Asia (Country 1)* & & & 0.965 \\
Eastern Mediterranean Region (country A) & 0.425 & & 0.923 \\
Eastern Mediterranean Region (Country B) & 0.923 & $1.017(0.46-2.21)$ & 0.973 \\
Eastern Mediterranean Region (Country C) & 0.001 & $1.547(1.07-2.22)$ & \\
South East Asia (Country 2) & 0.008 & $0.992(0.64-1.53)$ & 0.295 \\
Educational level & & & $0.013^{*}$ \\
Less than high school* & & & \\
More than high school & -0.158 & $0.854(0.63-1.14)$ & $<0.0001^{*}$ \\
High school & -0.346 & $0.921(0.464-0.954)$ & \\
Outdoor activity & & & \\
No & & & \\
Yes & -0.525 & $1(r) 0.59(0.47-0.74)$ & \\
\hline
\end{tabular}

*Reference category
Table 6 logistic regression analysis of socio-demographic and predictors of having COVID-19 sero-positivity population during the pandemic in Europe [16]. In Spain, a nationwide, population-based sero-epidemiological study from April 27 to May 11, 2020 included 35,883 households and the seroprevalence was $4.6 \%$ (95\% CI 4.3-5.0\%) [19]. A study from Switzerland between April 6 and May 9, 2020 reported a seroprevalence of $4.8 \%$ (95\% CI $2.4-8.0 \% ; n=341)$ in the first week, and $10.8 \%(95 \%$ CI $8.2-13.9 \%$; $n=775$ ) in the fifth week among 2766 participants [20]. In USA, a large study in March 23-May 12, 2020 showed a seroprevalence of $1 \%$ among 16,025 tested persons in the San Francisco Bay Area, 6.9\% in New York 
City [21] and $22.7 \%$ in Blaine County [8]. The highest seroprevalence was found to be $31.5 \%$ among 200 asymptomatic residents in Chelsea, Massachusetts [22]. Thus, the prevalence of anti-SARS-CoV-2 antibodies is variable depending on the country and the time of the study. The current study showed the possible vulnerability of migrant workers and those living in crowded areas in relation to SARS-CoV-2 infection. The disparity of SARS-CoV-2 infection and outcomes had been described in previous studies $[3,4,23]$. This disparity is important as a large percentage of the population in many developing countries are low-skilled migrant workers [17].

It is interesting to note that females had higher positivity rate than males ( $50.4 \%$ vs. $42.86 \%$; respectively; $P<0.0001)$. In a review article of 129 studies the sero-prevalence among females was $1.03(0.98-1.08)$ compared to males [18]. The differences may be related to the sociodemographic interactions or the difference in the underlying immune response between males and females [24]. A recent study from Saudi Arabia showed a higher seroprevalence among non-citizens compared to citizens (OR 13.6, $P=0.001$ ) [6]. The variation in seroprevalence was also noted across multiple zip codes and ethnicity in a study from Blaine County, Idaho, USA with a range from 28.4 to $34.8 \%$ [8]. The difference in seropositivity among slum and non-slum communities was significant with rates of $54.1 \%$ and $16.1 \%$, respectively [25]. These findings may be due to the fact that anti-SARSCoV-2 antibody seroprevalence varies according to the different study countries/ regions, study populations, timing during the period of the COVID19 pandemic, and methods used for serology testing [16].

Significant symptoms such as fever $\left(>38.5^{\circ} \mathrm{C}\right)$, runny nose, loss of smell and headache were associated risks with COVID-19 infection, as reported previously [26]. Nationality and race appeared to be important predictors of SARSCoV-2 infection risk. These finding are consistent with another study from USA where minorities might be more likely to live in communities with higher population density, poor air quality, work in jobs frequently contact with community, and lack access to healthcare which may increase the risk of infection [4]. For these reasons, high density population and underserved communities of colors may have additional barriers to social distancing measures and are more vulnerable to severe illness [27]. As with other infectious diseases, additional predictors of SARS-CoV-2 infection include age, nationality, education level and outdoor activity (frequent contact with the community). These factors may also influence the ability to seek care, adhere to treatment, and practice physical distancing measures [27].

In conclusion, risk of SARS-CoV-2 infection was higher among groups already affected by health disparities across age, nationality, educational level and employment status. Health promotion and disease prevention strategies should prioritize groups most vulnerable to infection and address structural inequities that contribute to risk through social and economic policy. Furthermore, effective strategies for predicting risk factors for community transmission should include both clinical and social factors. Culturally and linguistically appropriate interventions are essential, including communication materials of different formats and reading levels, as well as the use of community health workers that can engage with underserved groups. Regional differences in infection risk are evident as the seroprevalence varies according to different populations. Therefore, further continued surveillance of seroprevalence is warranted to estimate and monitor the growing burden of COVID-19.

Acknowledgements This serosurvey study was funded by the Saudi Ministry of Health

\section{Declarations}

Conflict of interest The authors declare that they have no conflict of interest.

\section{References}

1. Figueiredo-Campos P, Blankenhaus B, Mota C, Gomes A, Serrano $\mathrm{M}$, Ariotti S, et al. Seroprevalence of anti-SARS-CoV-2 antibodies in COVID-19 patients and healthy volunteers up to 6 months post disease onset. Eur J Immunol. 2020;50:2025-40. https://doi.org/ 10.1002/eji.202048970.

2. Ahmed SAKS, Ajisola M, Azeem K, Bakibinga P, Chen Y-F, Choudhury NN, et al. Impact of the societal response to COVID19 on access to healthcare for non-COVID-19 health issues in slum communities of Bangladesh, Kenya, Nigeria and Pakistan: results of pre-COVID and COVID-19 lockdown stakeholder engagements. BMJ Glob Health. 2020;5:e003042. https://doi. org/10.1136/bmjgh-2020-003042.

3. Al-Tawfiq JA, Leonardi R, Fasoli G, Rigamonti D. Prevalence and fatality rates of COVID-19: What are the reasons for the wide variations worldwide? Travel Med Infect Dis. 2020;35: 101711. https://doi.org/10.1016/j.tmaid.2020.101711.

4. Tirupathi R, Muradova V, Shekhar R, Salim SA, Al-Tawfiq JA, Palabindala V. COVID-19 disparity among racial and ethnic minorities in the US: a cross sectional analysis. Travel Med Infect Dis. 2020;38: 101904. https://doi.org/10.1016/j.tmaid.2020. 101904.

5. Ilesanmi OS, Oderinde TM, Afolabi AA. The urban slums: potential source of COVID-19 spikes in Africa. Public Health Pract. 2020;1:100052. https://doi.org/10.1016/j.puhip.2020.100052.

6. Banjar A, Al-Tawfiq JA, Alruwaily A, Alserehi H, Al-Qunaibet A, Alaswad R, et al. Seroprevalence of antibodies to SARS-CoV-2 among blood donors in the early months of the pandemic in Saudi Arabia. Int J Infect Dis. 2021;104:452-7. https://doi.org/ 10.1016/j.ijid.2021.01.028.

7. Alserehi HA, Alqunaibet AM, Al-Tawfiq JA, Alharbi NK, Alshukairi AN, Alanazi KH, et al. Seroprevalence of SARS-CoV-2 (COVID-19) among healthcare workers in Saudi Arabia: comparing case and control hospitals. Diagn Microbiol Infect Dis. 2021;99: 115273. https://doi.org/10.1016/j.diagmicrobio.2020. 115273. 
8. McLaughlin CC, Doll MK, Morrison KT, McLaughlin WL, O'Connor T, Sholukh AM, et al. High Community SARS-CoV-2 Antibody Seroprevalence in a Ski Resort Community, Blaine County, Idaho, US. Preliminary Results. MedRxiv Prepr Serv Health Sci. 2020. https://doi.org/10.1101/2020.07.19.20157198.

9. Assiri A, Al-Tawfiq JA, Alkhalifa M, Al Duhailan H, Al Qahtani S, Dawas RA, et al. Launching COVID-19 vaccination in Saudi Arabia: lessons learned, and the way forward. Travel Med Infect Dis. 2021;43: 102119. https://doi.org/10.1016/j.tmaid.2021. 102119.

10. Saudi Ministry of Health. COVID-19 Coronavirus Guidelines 2021. https://www.moh.gov.sa/Ministry/MediaCenter/Publicatio ns/Documents/Coronavirus-Disease-2019-Guidelines-v1.2.pdf. Accessed 5 June 2021.

11. Almohaya AM, Qari F, Zubaidi GA, Alnajim N, Moustafa K, Alshabi MM, et al. Early solicited adverse events following the BNT162b2 mRNA vaccination, a population survey from Saudi Arabia. Prev Med Rep. 2021;24: 101595. https://doi.org/10. 1016/J.PMEDR.2021.101595.

12. Al Bahrani S, Albarrak A, Alghamdi OA, Alghamdi MA, Hakami FH, Al Abaadi AK, et al. Safety and reactogenicity of the ChAdOx1 (AZD1222) COVID-19 vaccine in Saudi Arabia. Int J Infect Dis. 2021;110:359-62. https://doi.org/10.1016/j.ijid. 2021.07.052.

13. Muench P, Jochum S, Wenderoth V, Ofenloch-Haehnle B, Hombach M, Strobl M, et al. Development and validation of the elecsys anti-SARS-CoV-2 immunoassay as a highly specific tool for determining past exposure to SARS-CoV-2. J Clin Microbiol. 2020;58:1694-714. https://doi.org/10.1128/JCM.01694-20.

14. Lau C, Hoo S, Yew S, Ong S, Lum L, Heng P, et al. Evaluation of the Roche Elecsys anti-SARS-CoV-2 assay. MedRxiv. 2020. https://doi.org/10.1101/2020.06.28.20142232.

15. Riester E, Findeisen P, Hegel JK, Kabesch M, Ambrosch A, Rank CM, Pessl F, Laengin T, Niederhauser C. Performance evaluation of the Roche Elecsys Anti-SARS-CoV-2 S immunoassay. J Virol Methods. 2021;297:114271. https://doi.org/10.1016/j.jviromet. 2021.114271.

16. Lai CC, Wang JH, Hsueh PR. Population-based seroprevalence surveys of anti-SARS-CoV-2 antibody: an up-to-date review. Int J Infect Dis. 2020;101:314-22. https://doi.org/10.1016/j.ijid.2020. 10.011 .

17. Alali WQ, Bastaki H, Longenecker JC, Aljunid SM, AlSeaidan $\mathrm{M}$, Chehadeh W, et al. Seroprevalence of SARS-CoV-2 in migrant workers in Kuwait. J Travel Med. 2021;28:1-3. https://doi.org/10. 1093/jtm/taaa223.
18. Bobrovitz N, Arora RK, Cao C, Boucher E, Liu M, Donnici C, et al. Global seroprevalence of SARS-CoV-2 antibodies: a systematic review and metaanalysis. PLoS ONE. 2021;16: e0252617. https://doi.org/10.1371/journal.pone.0252617.

19. Pollán M, Pérez-Gómez B, Pastor-Barriuso R, Oteo J, Hernán MA, Pérez-Olmeda M, et al. Prevalence of SARS-CoV-2 in Spain (ENE-COVID): a nationwide, population-based seroepidemiological study. Lancet. 2020;396:535-44. https://doi.org/10.1016/ S0140-6736(20)31483-5.

20. Stringhini S, Wisniak A, Piumatti G, Azman AS, Lauer SA, Baysson $\mathrm{H}$, et al. Seroprevalence of anti-SARS-CoV-2 IgG antibodies in Geneva, Switzerland (SEROCoV-POP): a population-based study. Lancet. 2020;396:313-9. https://doi.org/10.1016/S01406736(20)31304-0.

21. Havers FP, Reed C, Lim T, Montgomery JM, Klena JD, Hall AJ, et al. Seroprevalence of Antibodies to SARS-CoV-2 in 10 Sites in the United States, March 23-May 12, 2020. JAMA Intern Med. 2020;180:1776-86. https://doi.org/10.1001/jamainternmed.2020. 4130.

22. Naranbhai V, Chang CC, Beltran WFG, Miller TE, Astudillo MG, Villalba JA, et al. High seroprevalence of anti-SARS-CoV-2 antibodies in Chelsea, Massachusetts. J Infect Dis. 2020;222:1955-9. https://doi.org/10.1093/infdis/jiaa579.

23. Millett GA, Jones AT, Benkeser D, Baral S, Mercer L, Beyrer $\mathrm{C}$, et al. Assessing differential impacts of COVID-19 on black communities. Ann Epidemiol. 2020;47:37-44. https://doi.org/10. 1016/j.annepidem.2020.05.003.

24. Takahashi T, Ellingson MK, Wong P, Israelow B, Lucas C, Klein J, et al. Sex differences in immune responses that underlie COVID-19 disease outcomes. Nature. 2020;588:315-20. https:// doi.org/10.1038/s41586-020-2700-3.

25. Malani A, Shah D, Kang G, Lobo GN, Shastri J, Mohanan M, et al. Seroprevalence of SARS-CoV-2 in slums versus non-slums in Mumbai, India. Lancet Glob Health. 2021;9:e110-1. https:// doi.org/10.1016/S2214-109X(20)30467-8.

26. Wolff D, Nee S, Hickey NS, Marschollek M. Risk factors for Covid-19 severity and fatality: a structured literature review. Infection. 2021;49:15-28. https://doi.org/10.1007/ s15010-020-01509-1.

27. Rozenfeld Y, Beam J, Maier H, Haggerson W, Boudreau K, Carlson J, et al. A model of disparities: risk factors associated with COVID-19 infection. Int J Equity Health. 2020. https://doi.org/ 10.1186/s12939-020-01242-z. 